\title{
ISOLASI DAN IDENTIFIKASI JAMUR KAYU DARI HUTAN PENDIDIKAN DAN LATIHAN TABO-TABO KECAMATAN BUNGORO KABUPATEN PANGKEP
}

\author{
Isolation and Identification of Wood decayed-Fungy from Tabo-tabo Educational Forest at Bugoro \\ Subdistrict, Pangkep Regency
}

Astuti Arif, Musrizal Muin, Tutik Kuswinanti, dan Vitri Harfiani

\begin{abstract}
Wood deterioration were generally occured by the activities of biological agents. Fungal can attack wood and lignoselulosic substances and cause staining and decaying. Its damage levels were vary depending on the attacking fungal species. Eventhough it poses some disadvantages, actually fungy have potential benefits for human life such as nutrient, energy resources, medicine, etc. Fungy from Tabo-tabo educational forest were collected, isolated,and identified in this study. Identification was conducted throughout their macroscopic and microscopic characteristics. The result showed that the amount of fungal species were nineteen species, i.e: Aspergillus sp.,Poria subacida, Fomes sp., Lenzites sp., Hericium sp., Dacrymyces deliquescens, Ganoderma lucidum, Clitocybe sp., Trametes confragasa, Shizophyllum commune, Periconia sp., dan Helicosporium sp.,Clitocybe sp., Schizophyllum commune, dan Hygrophorus hypotejus, Ganoderma lucidum dan Coprinus atramentarius, Amanitopsis fulva dan Dacrymyces deliquescens, Collybia sp., Amanitopsis fulva, Hygrophorus hypotejus, Coprinus atramentarius, Monilia sitophilia, Gilmaniella sp. dan Conoplea sp.
\end{abstract}

Key words: Wood fungy, deterioration, Tabo-tabo Educational Forest

\section{PENDAHULUAN}

Jamur merupakan organisme yang tidak berklorofil sehingga jamur tidak dapat menyediakan makanan sendiri dengan cara fotosintesis seperti pada tanaman yang berklorofil. Oleh karena itu, jamur mengambil zat-zat makanan yang sudah jadi yang dibuat atau dihasilkan oleh organisme lain untuk kebutuhan hidupnya. Sifat ketergantungan terhadap organisme lain menyebabkan jamur digolongkan sebagai tumbuhan heterotrofik (Djarijah dan Djarijah, 2001). Menurut Zabel dan Morrel (1992), sebagai tumbuhan heterotrofik, jamur membutuhkan sumber makanan sebagai substrat, sumber energi, aktivitas metabolisme, dan nutrisi. Energi dapat diperoleh dari oksidasi senyawa karbon, metabolisme untuk mensintesis senyawa-senyawa yang dibutuhkan untuk pertumbuhan dan perkembangan hifa jamur, dan sumber nutrisi yang dibutuhkan seperti vitamin, $\mathrm{CO}_{2}$, dan nitrogen. Selain dikenal sebagai salah satu organisme perusak kayu yang merugikan, jamur juga termasuk salah satu komoditi Indonesia yang sekarang ini banyak dibudidayakan dan dikonsumsi oleh manusia karena jamur banyak mengandung nilai gizi yang tinggi dan bermanfaat bagi kesehatan.

Suhu merupakan faktor utama dalam pertumbuhan jamur. Pada kondisi-kondisi alami, jamur perusak kayu dapat berkembang pada kisaran suhu yang cukup tinggi. Suhu optimum berbeda-beda untuk setiap spesies, tetapi pada umumnya terletak antara $22^{\circ} \mathrm{C}$ dan $35^{\circ} \mathrm{C}$ (Bedyaman dan Nandika, 1989). Oleh karena itu, jenis jamur yang tumbuh pada satu tempat bisa saja berbeda dengan jenis jamur yang tumbuh pada tempat lain karena setiap tempat memiliki suhu yang berbeda atau pun sama. Pada penelitian ini dipilih lokasi Hutan Pendidikan dan Latihan Tabo-tabo. Selain sebagai tempat pendidikan, penelitian ini akan memberikan informasi tentang potensi keanekaragaman jamur yang dapat tumbuh pada hutan tersebut.

\section{BAHAN DAN METODE}

\section{Pengambilan Sampel Jamur di Lapangan}

Sampel jamur diambil dengan menggunakan metode purposif pada kayu yang terserang jamur 
dan tanah yang mengandung serasah atau bahan organik di beberapa lokasi pada Hutan Pendidikan dan Latihan Tabo-tabo, Kecamatan Bungoro, Kabupaten Pangkep, Sulawesi Selatan.

\section{Persiapan Medium Tumbuh}

Medium tumbuh yang digunakan adalah Potato Dextrose Agar (PDA). Medium tumbuh dibuat dengan campuran bahan-bahan yaitu kentang yang telah dikupas $200 \mathrm{~g}$, gula pasir $20 \mathrm{~g}$, tepung agar $16 \mathrm{~g}$, aquades $1000 \mathrm{ml}$. Pembuatan medium didasarkan pada prosedur Dharmaputra, dkk. (1989), yaitu: kentang diris-iris setebal $1 \mathrm{~cm}$, direbus sampai diperoleh air rebusan yang kekuning-kuningan yaitu ketika kentang mulai lunak. Air rebusan kentang disaring dengan menggunakan kain saring. Filtrat hasil saringan air rebusan kentang tersebut ditambahkan dengan gula pasir dan tepung agar kemudian semua bahan dipanaskan dan di aduk sampai larut. Setelah semua bahan-bahan larut, medium tumbuh tersebut disterilkan di autoclave selama \pm 15 menit pada suhu $121^{\circ} \mathrm{C}$ dengan tekanan $1,5 \mathrm{~atm}$. Saat medium tumbuh dalam keadaan hangat diberi streptomycin sulfate yang berfungsi sebagai antibiotik penghambat bakteri kontaminan. Kemudian larutan medium tumbuh dituang dalam cawan steril, selanjutnya dibiarkan pada laminator air flow sampai memadat.

\section{Isolasi Jamur di Laboratorium}

Isolasi dan identifikasi jenis-jenis jamur yang diperoleh dari lapangan dilaksanakan di Laboratorium Bioteknologi Pertanian, Pusat Kegiatan Penelitian, Universitas Hasanuddin, dengan tahapan:
Isolasi Jamur dari kayu/pohon

Metode ini digunakan pada sampel jamur yang sudah membentuk tubuh buah. Sampel jamur yang sudah di potong kecil-kecil sebelum dibiakkan dilakukan Sterilisasi permukaan dengan menggunakan air steril dan alkohol $70 \%$. Pembiakannya bisa dilakukan dengan kertas saring atau langsung pada media biakan (PDA). Pemindahan koloni baru dilakukan berulangulang sampai diperoleh isolat murni.

\section{Identifikasi Jamur}

Identifikasi dilakukan dengan mengamati ciri makroskopis dan mikroskopis jamur. Ciri makroskopis yang diamati adalah warna jamur, koloni jamur dan bentuk tubuh buah jamur. Pengamatan ciri mikroskopis mencakup hifa, spora, sporangium, konidia dan konidiofor dan ciri khusus yang akan menentukan jenis jamur tersebut. Mendokumentasikan sampel dengan menggunakan mikroskop berkamera. Identifikasi dilakukan dengan mengacu pada buku identifikasi jamur, yaitu: Barnett and Hunter (1998), Streets (1980), Fassatiova (1986), Dharmaputra, dkk. (1989), Sastrahidayat (1990), Savonius (1973), KEHATI (2000).

\section{HASIL DAN PEMBAHASAN}

Pada dasarnya, jamur yang diperoleh dari Hutan Pendiikan Tabo-Tabo dapat dikenali dan diidentifikasi dalam tiga cara, yaitu mengenali jamur berdasarkan ciri makroskopis atau ciri mikroskopisnya saja, serta dari keduanya, yang secara detail dapat dilihat pada Gambar 1, 2 dan 3 . 


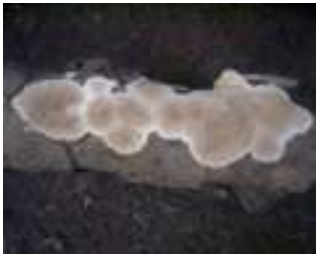

Poria subacida

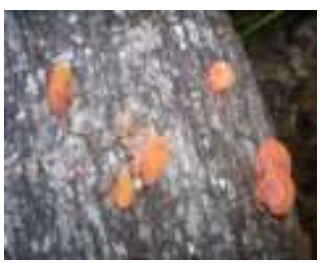

Dacrymyces liquescens

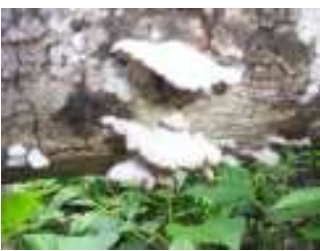

Clitocybe sp.

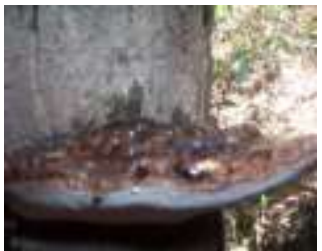

Fomes sp

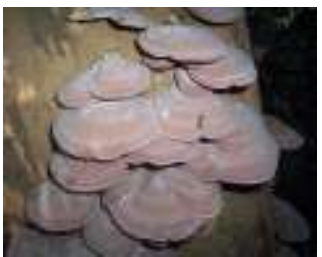

Ganoderma lucidum

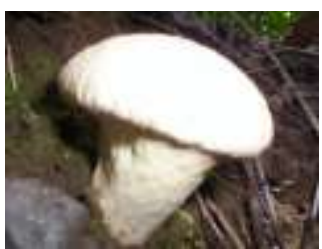

Trametes confragasa

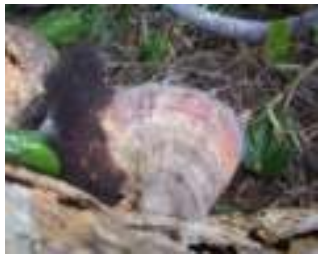

Lenzites sp.

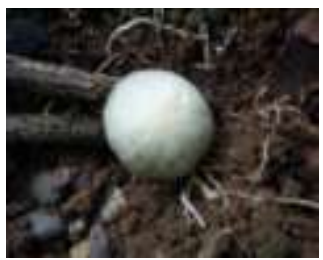

Collybia sp.

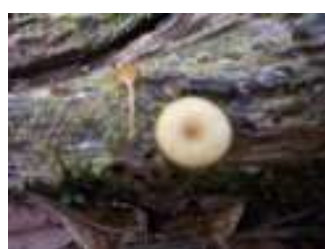

Schizophyllum commune Hygrophorus hypotejus

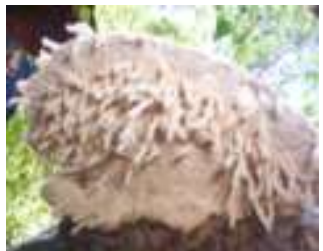

Hericium sp.

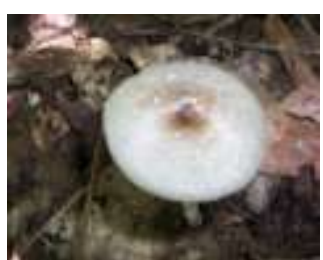

Amanitopsis fulva

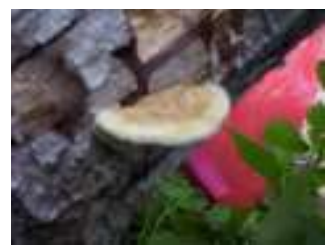

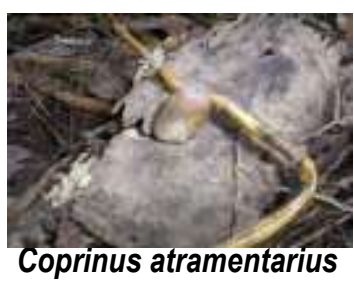

Figure 1. Identified fungal by macroscopic caracteristics

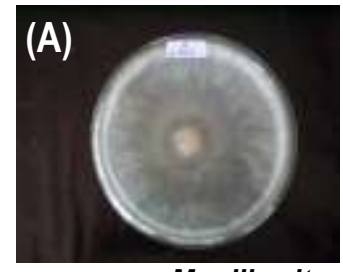

Monilia sitophilia

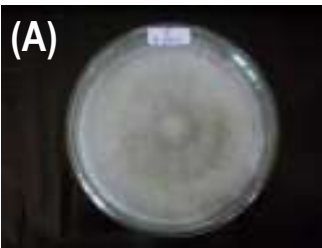

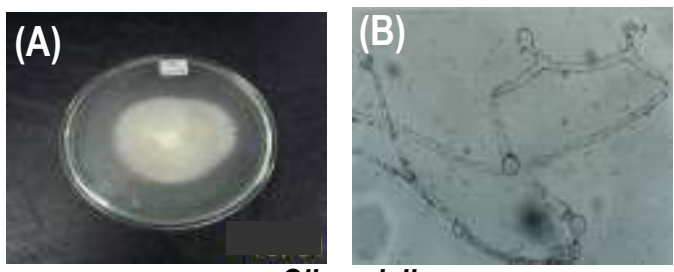

Gilmaniella sp.

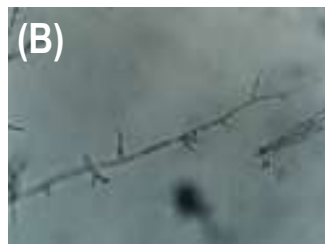

\section{Conoplea sp.}

Figure 2. Identified fungal by microscopic caracteristics: (A) mycelium growth after 14 days, and (B) microskopic appearence with 400X magnification. 

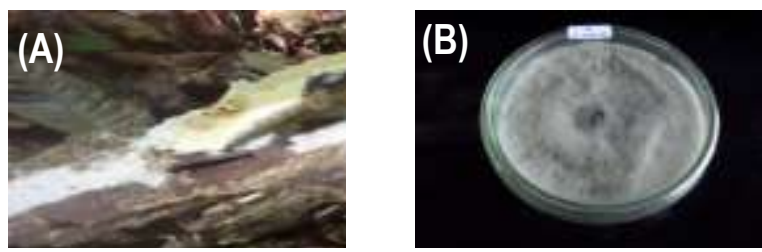

Periconia sp.
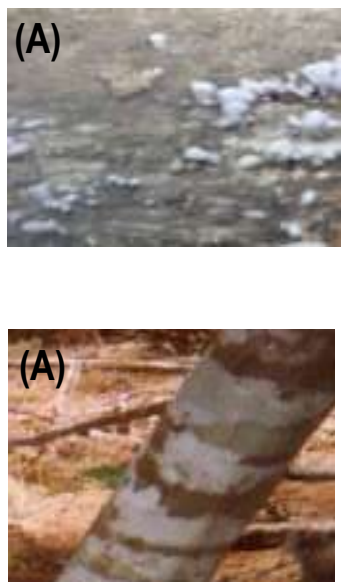

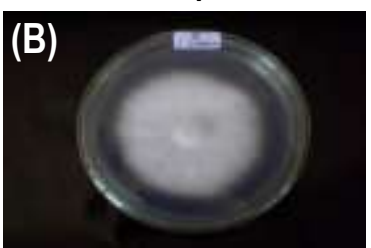

Helicosporium sp.

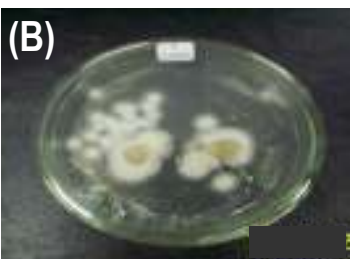

Aspergillus sp.
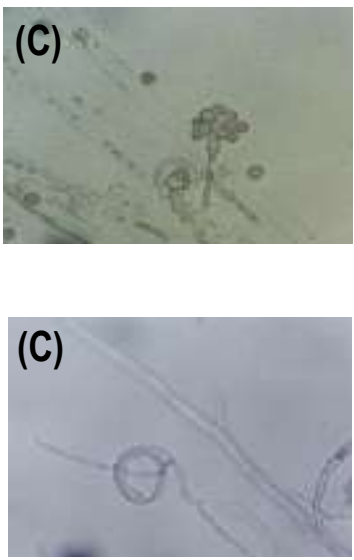

(C)

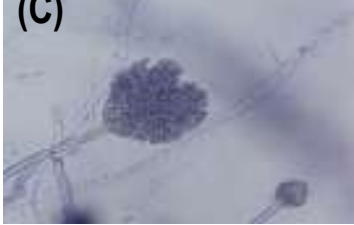

Figure 3. Identified fungal by both of macroscopic and microscopic caracteristics. (A) macroskopic appearance, (B) mycelial growth after 14 days, (C) microskopis appearence with 200X magnification.

Secara ringkas hasil penelitian ini menunjukan bahwa jenis-jenis jamur yang ada di Hutan Pendidikan dan Latihan Tabo-tabo Kecamatan Bungoro Kabupaten Pangkep dapat digolongkan atas jamur pewarna (Aspergillus sp.), dan jamur pelapuk kayu (Poria subacida, Fomes sp., Lenzites sp., Hericium sp., Dacrymyces deliquescens, Ganoderma lucidum, Clitocybe sp., Trametes confragasa, Schizophyllum commune, Periconia sp., Helicosporium sp.). Beberapa jenis jamur yang ditemukan belum diketahui hubungannya dengan deteriorasi kayu, yaitu Collybia sp., Amanitopsis fulva, Hygrophorus hypotejus, Coprinus atramentarius, Monilia sitophilia, Gilmaniella sp., dan conoplea sp. Jamur yang diidentifikasi tersebut juga ada yang dapat dikonsumsi (Clitocybe sp., Schizophyllum commune, dan Hygrophorus hypotejus), sebagai obat (Ganoderma lucidum dan Coprinus atramentarius), dan ada yang beracun (Amanitopsis fulva dan Dacrymyces deliquescens). Pengelompokan jamur menurut kemampuannya merusak kayu dapat dilihat pada Tabel 1.
Pada Tabel 1 juga dapat dilihat bahwa jamur-jamur yang telah diidentifikasi ini ada yang ditemukan pada satu pohon yang sama seperti pada pohon Dracontomelon dao. Jenis-jenis jamur yang ditemukan pada pohon tersebut yaitu Poria subacida, Fomes sp., dan Ganoderma lucidum. Jamur Lenzites sp., Hericium sp., dan Dacrymyces deliquescens ditemukan pada pohon Anacardium ocidentale. Pada pohon Acacia auriculiformis ditemukan jenis jamur Clitocybe sp., Trametes confragasa dan Helicosporium $\mathrm{sp}$. Jamur yang ada pada permukaan tanah yaitu Hygrophorus hypotejus, Coprinus atramentarius dan Conoplea sp. Jamur Periconia sp., dan Aspergillus sp. ditemukan pada pohon Pterocarpus indicus. Ada juga jenis jamur yang hanya ditemukan pada satu pohon seperti jenis jamur yang ditemukan pada pohon Ficus sp. adalah Schizophyllum commune. Selain itu juga dijumpai jenis jamur yang tumbuh pada serasah ranting pohon lapuk yaitu jamur Collybia sp. dan serasah daun Tectona grandis jenis jamur Amanitopsis fulva. Dan ada juga yang ditemukan pada 
tumpukan serasah daun-daun yaitu Monilia sitophilia dan Gilmaniella sp.

Table 1. Fungal classification based on wood damage characteristics

\begin{tabular}{|c|c|c|c|c|c|}
\hline \multicolumn{6}{|c|}{ Classification } \\
\hline No. & Fungal species & $\begin{array}{l}\text { Wood } \\
\text { staining } \\
\text { fungi }\end{array}$ & $\begin{array}{c}\text { Wood } \\
\text { decaying } \\
\text { fungi }\end{array}$ & Location & Class \\
\hline 1. & Poria subacida & - & $\sqrt{ }$ & Dracontomelon dao & Basidiomycetes \\
\hline 2. & Fomes sp. & - & $\sqrt{ }$ & Dracontomelon dao & Basidiomycetes \\
\hline 3. & Lenzites sp. & - & $\sqrt{ }$ & Anacardium ocidentale & Basidiomycetes \\
\hline 4. & Hericium sp. & - & $\sqrt{ }$ & Anacardium ocidentale & Basidiomycetes \\
\hline 5. & Dacrymyces deliquescens & - & $\sqrt{ }$ & Anacardium ocidentale & Basidiomycetes \\
\hline 6. & Ganoderma lucidum & - & $\sqrt{ }$ & Dracontomelon dao & Basidiomycetes \\
\hline 7. & Collybia sp. & - & - & Serasah ranting pohon lapuk & Basidiomycetes \\
\hline 8. & Amanitopsis fulva & - & - & Serasah daun T. grandis & Ascomycetes \\
\hline 9. & Clitocybe sp. & - & $\sqrt{ }$ & Acacia auriculiformis & Basidiomycetes \\
\hline 10. & Trametes confragasa & - & $\sqrt{ }$ & Acacia auriculiformis & Basidiomycetes \\
\hline 11. & Schizophyllum commune & - & $\sqrt{ }$ & Ficus sp. & Basidiomycetes \\
\hline 12. & Hygrophorus hypotejus & - & - & Tanah & Basidiomycetes \\
\hline 13. & Coprinus atramentarius & - & - & Tanah & Basidiomycetes \\
\hline 14. & Monilia sitophilia & - & - & Tumpukan serasah daun & Deuteromycetes \\
\hline 15. & Periconia sp. & - & $\sqrt{ }$ & Pterocarpus indicus & Deuteromycetes \\
\hline 16. & Helicosporium sp. & - & $\sqrt{ }$ & Acacia auriculiformis & Deuteromycetes \\
\hline 17. & Gilmaniella sp. & - & - & Tumpukan serasah daun & Deuteromycetes \\
\hline 18. & Conoplea sp. & - & - & Tanah & Deuteromycetes \\
\hline 19. & Aspergillus sp. & $\sqrt{ }$ & - & Pterocarpus indicus & Deuteromycetes \\
\hline
\end{tabular}

\section{DAFTAR PUSTAKA}

Anonim. 2002. Dinkes Kumpulkan Informasi Kasus Jamur. Http/www. Harian Umum Suara Merdeka. Com/2002/Desember/Dinkes.htm.

2004. Kayu Karet Dapat Menggantikan Kayu Hutan Alam. Balai Penelitian Sumbawa. Sumbawa.

Bedyaman T. dan D. Nandika. 1989. Bahan Pengajaran: Deteriorasi Kayu oleh Faktor Biologis. Departemen Pendidikan dan Kebudayaan. Direktorat Jenderal Pendidikan Tinggi. Pusat Antar Universitas Bioteknologi. IPB. Bogor.

Barnett, H.L. dan B.B. Hunter. 1998. Illustrated Genera of Imperfect Fungi. The American Phytopathological Society St. Paul, Minnesota.

Burhanuddin. 2004. Revolusi Lingzhi DXN Lingzhi Revolution. USM. Malaysia.

Dharmaputra O.S; W.G. Agustin dan Nampiah. 1989. Penuntun Praktikum: Mikologi Dasar. Departemen Pendidikan dan Kebudayaan. Direktorat Jenderal Pendidikan Tinggi Pusat Antar Universitas IImu Hayati. IPB. Bogor.
Dumanauw, J.F. 1990. Mengenal Kayu. Penerbit Kanisius. Yogyakarta.

Djarijah, N.M. dan A.S. Djarijah. 2001. Budidaya Jamur Tiram. Kanisius. Yogyakarta.

Elsppat. 1997. Pengawetan Kayu dan Bambu. Puspa Swara. Jakarta.

Fassatiova, O. 1986. Moulds and Filamentous Fungi in Technical Microbiology. Department of Cryptogamic Botany Charles University. Prague.

Fisher, F. dan C. Norman. 1998. Fundamentals of Diagnostic Micologi. W.B Saunders Company. A Divisiooon of Harcourt Brace and Company, Philadelphia.

Hunt, G.M. dan G.A.Garrant. 1967. Wood Preservation. Third Edition. McGraw Hill Book Company. New York.

KEHATI. 2000. Jamur Makroskopis (Cendawan) di TNKS, Small Research 1999/2000. Dirjen PHKA Departemen Kehutanan dan Yayasan Keanekaragaman Hayati. Sumatera Selatan.

Kollman, F.F.P. 1968. Principles of Wood Science and Technology. In: Chemistry of 
Solid Wood. R. Rowell (ed). Spring Ervering Berlin Heidelberg. New York.

Martoredjo, T. 1996. Ilmu Penyakit Tumbuhan.

Edisi Ketiga. Gadjah Mada University Press. Yogyakarta.

Savonius, M. 1973. All Colour Book of Mushrooms and Fungi. Octopus Books. London.

Sastrahidayat, I.R. 1990. IImu Penyakit Tumbuhan. Usaha Nasional Surabaya. Surabaya.
Streets, R.B. 1980. Diagnosis Penyakit Tanaman. The University of Arizona Press. Tuskon-Arizona, USA. (Alih bahasa: Imam Santoso)

Suhardiman, P. 1983. Jamur Kayu. Penebar Swadaya. Jakarta.

Zabel, R. A. dan J.J. Morrel. 1992. Wood Microbiology: Decay and its Preservation. Academic Press, Inc. San Diego.

Diterima : 03 Mei 2007

Astuti Arif, Musrizal Muin, dan Vitri Harfiani

Lab. Keteknikan dan Diversifikasi produk Hasil Hutan

Fakultas Kehutanan, Universitas Hasanuddin

Kampus Tamalanrea, Jl. Perintis Kemerdekaan Km. 10, Makassar 90245

Telp./Fax. 0411-585917. Indonesia

Tutik Kuswinanti

Lab. Bioteknologi Pertanian

Pusat Kegiatan Penelitian, Universitas Hasanuddin

Kampus Tamalanrea, Jl. Perintis Kemerdekaan Km. 10, Makassar 90245

Telp./Fax. 0411-585917. Indonesia 